https://doi.org/10.48009/2_iis_2009_390-399

\title{
HOSPITAL ADMINISTRATORS' PERCEPTION ON THE ADOPTION OF RFID: EMPIRICAL STUDY INCLUDING PRIVACY/SECURITY
}

\author{
Sun Gi Chun, Alabama State University, sungichun@alasu.edu \\ Dalsang Chung, Governor State University, D-Chung@govst.edu
}

\begin{abstract}
Various areas including retail, manufacturing, healthcare, service, and government have used RFID. Hospitals have adopted RFID technology to improve management of medical equipment and patient service. Even though the technology has provided various benefits, privacy/security issues regarding patients have been involved. The authors had a research question as to whether privacy/security factors were as important as environmental, organizational, and technological factors for hospital administrators to make technology adoption decisions. As a modified version of innovation diffusion theory, the authors developed a research model that added ethical/legal/privacy/social factors to environmental, organizational, and technological factors. Survey questionnaires were mailed out to 1,068 hospital administrators in the Northwest areas of the U.S. and 75 responded. As a result of factor analysis and canonical discriminant analysis, ethical/legal/ privacy/social factors were as important as other environmental, technological, and organizational factors for the technology adoption decision. Moreover, hospital administrators who have not adopted RFID, but have the intention to adopt RFID were more concerned about privacy policies for patients and employees. They were ethically anxious about getting employees' consent before the adoption of RFID applications, because hospital administrators can locate employees on the real time basis by RFID applications.
\end{abstract}

Keywords: Radio Frequency Identification (RFID), Hospital, Empirical, Privacy

\section{INTRODUCTION}

Radio Frequency Identification (RFID) technology has been used in various areas such as manufacturing, retailing, healthcare, service, and government. Among them, hospitals have adopted RFID in the areas of nursery, emergency/operation rooms, material/equipment management, and pharmacy for the purpose of real time based tracking of patients/employees, medical equipment, and materials while the technology has been slowly adopted by hospitals [2]. Even though many authors in the academic and trade journals talk of benefits derived from the adoption of the technology, they also raise ethical, legal, privacy, and social issues that might hinder hospitals from adopting the technology $[1,4,5,8]$. Ethical, legal, privacy, and social aspects of RFID have been carefully considered when hospital administrators make the technology adoption/diffusion decision [4]. There are few empirical researches on examining those issues related to technology adoption decision in the hospital. The objective of the study is to conduct surveys on the hospital administrators' perception of RFID technology and its adoption decision, and examination of ethical, legal, privacy, and social factors contributing to the decision.

\section{LITERATURE REVIEW}

RFID has been used in retailing, government, and healthcare industries. As leading adopters of RFID, retailers such as Wal-Mart and Target mandated major suppliers to utilize RFID technology for the improvement of inventory management. The Department of Defense has also mandated major suppliers to adopt this technology. The United Kingdom, United States, Australia, and Malaysia have used RFID tags in their passports. The healthcare and pharmaceutical industry has been one of the most promising areas to apply RFID technology because the technology would improve patient safety, process efficiency, management of critical care assets and hospital equipment, and reduction of counterfeiting and theft of pharmaceutical products [6].

RFID systems consist of radio frequency readers in the form of hand-held devices or mounted receivers similar to wireless access points and RFID tags that are made up of microchips and antennas [13]. The technology can be either active or passive. In active systems, RFID tags send out signals to readers by battery power. Passive tags work without batteries. The tags are activated by radio signals sent by mounted or hand-held radio frequency readers. Even if RFID tags are hidden, the tags can be read. The tags reading and writing capabilities can be reused to store much more information than bar code. 
According to the monitoring technology developed by Accenture Technology Lab, RFID technology with cameras and sensors can keep track of valuable assets and ensure that employees are properly following procedures. In particular, valuable and sophisticated health care equipment and facilities will be monitored by the technology to identify their location, and the face recognition technology will identify employees who follow the required procedure for borrowing or removing the assets from one location to another [14].

\section{RFID and Technology Adoption Theories}

Hospitals can apply RFID technology to better manage inventory by increasing inventory visibility and obtaining accurate inventory data. Medical equipment on the portable carts in hospitals can be traced by attached smart tags by RFID readers installed in the doorways, which would allow personnel to quickly locate critical pieces of equipment and determine their fitness for use. RFID technology can be utilized to identify and locate patients to ensure patient safety when urgent medical attention is especially needed. Physicians can scan patients' RFID tags and view such surgical information on the computer as surgery date, type of procedure, and name of surgeon, which can be used to help reduce medical errors by ensuring the right procedure is being done on the right patient in the right location. A medical doctor in Palm beach Orthopedic Institute said, "I am not interested in using a RFID network to track patients, and I am just trying not to take out a wrong kidney on a patient [13]." Furthermore, besides patient and personnel tracking, RFID can be used for patient admission and registration, patient self service like bill payment, dosage and disposal of medicine, and updating medical records. Therefore, RFID technology can improve operational efficiency by locating key personnel and mobile critical equipment on a real time basis, which results in competitive advantage under the circumstances of a cost-tightened hospital environment [6].

The adoption of RFID in hospitals has been slow because of such factors as high tag costs, wireless networking infrastructure, application software and hardware costs, and the lack of standards on RFID tags [2]. Many hospitals have been aware of the technology; however, before adopting the technology, they wait to see if hospitals that have installed the technology in the form of the pilot project prove enough benefits [13]. Another reason for the slow adoption of the technology is the privacy issue raised by the technology. Hospital administrators are concerned about the privacy of patients and employee/staff. Furthermore, implantation of RFID chips in the human body has raised numerous controversies and ethical issues, which might hinder the adoption of the technology [6]. With RFID technology, hospital administrators can monitor nurses and other employees by locating them on the real time basis, which puts pressure on them to do intensive labor and leads to privacy and social controversy [4]. The Health Insurance Portability and Accountability Act (HIPAA) strongly enforces hospitals to safeguard confidential patient and employee data by restricting access to the data only in the minimum necessary case and carefully disposing their personal information. The Act directed hospitals and other companies in the healthcare industry to establish policy and procedures to avoid penalties on violation of the law $[1,5]$.

RFID as relatively new information technology (IT) has been slowly adopted and used in hospitals while the technology has still been reviewed and tested in terms of its feasibility including cost and benefit analysis by hospital administrators or IT managers. Numerous authors have tried to build theories on innovation, adoption/diffusion decision, and technology acceptance behavior because technology in its nature has been continuously researched, developed, and commercialized [8, 9, 10, 12, 15]. The efforts to build theories have been rewarded when managers or users can employ the theory to make the adoption/diffusion decision after thoroughly examining the effect of the emerging IT on their business.

Technology adoption and diffusion literature has focused on the perception of potential adopters on emerging technology, because the perception of the potential adopters has impacted the adoption decision. Measuring the potential adopter's perception on technology has been one of the basic issues. While some technologies are simple enough for an individual to make an adoption decision, other technologies are complex enough for organization to make an adoption decision such as RFID. Rogers [12] studied the perception of the potential adopter of the technology and suggested five characteristics of innovation, that is, relative advantage, compatibility, complexity, observability, and trialability. Moore \& Benbasat [10] tried to remove technology specific characteristics from the study when they developed the instrument for measuring perception of technology adopters. The authors picked twenty-five (25) items representing eight (8) characteristics of technology adopters including voluntariness, result demonstrability, and image in addition to Roger's 
five (5) characteristics of innovation adopters. Ventatesh et al. [15] attempted to unite various models to Unified View so that they considered intention to adopt or usage as dependent variables while they focused on individual technology decisions and other moderating variables such as age, gender and social influence. Recently, Lee \& Shim [8] considered organizational and environmental factors that included organizational readiness, financial resources, performance gap, market uncertainty, need pull, vendor pressure, and perceived benefits.

\section{RESEARCH METHODOLOGY}

Besides environmental, organizational, and technological factors, the study will include ethical and social aspects of RFID technology because the technology has brought up its own strong ethical, legal, privacy, and social issues. Also, the authors employed three (3) innovation adoption stages as a dependent variable, 1) having not adopted yet and no intention to adopt, 2) having not adopted yet, but having an intention to adopt, and 3) having adopted. Therefore, the research model for the study was as follows in Figure 1:

Our research centered upon the following research question: What are important factors to make this technology adoption decision? The research hypothesis to be tested was as follows:

$\mathrm{H}_{1}$ : Ethical/Legal/Privacy/Social factors are important to make the technology adoption decision just like other environmental, technological, and organizational factors.

The survey instrument was designed to have forty (40) items to measure four (4) major factors and three (3) categories of technology adoption stages: 1) having not adopted yet and no intention to adopt, 2) having not adopted yet, but having an intention to adopt, and 3) having adopted. Forty (40) items to measure the decision makers' perception of major adoption factors were statements for respondents to reply on a 5 point Likert scale, that is, one (1) for strongly agree and five (5) for strongly disagree. Two (2) items were designed separately to find technology adoption stages and decision makers' intention to adopt the RFID technology if they have not yet adopted the technology.

The authors mailed out survey questionnaires to 1,068 subjects who worked for hospitals with titles of Hospital Administrators, Chief Information Officers
(CIOs), DP Directors, IT Directors, IT/Network Managers, and Telecommunication managers in the Midwest states such as Illinois, Indiana, Iowa, and Wisconsin. The mailing label to target IT decision makers in hospitals was purchased by a hospital marketing company.

\section{DATA ANALYSIS}

Out of 1,068 subjects, 82 responded. After reviewing the questionnaire, 75 were usable for the data analysis. 75 respondents consisted of 15 Hospital Administrators, 23 CIOs, 12 IT Directors, 18 IT/Network managers, 2 DP Directors and 5 Telecommunication Directors. 36 respondents aged between 50 and 59 and 27 were between 40 and 49 while 6 aged more than 60 and 6 aged less than 40 . Detailed demographics of the respondents are in Table 1.

39 respondents worked for hospitals in Illinois, and 14 worked in Iowa, while 13 did in Wisconsin, and 9 did in Indiana. 30 were in Metropolitan areas, while 45 were in rural areas. 21 hospitals were teaching institutions, while 54 hospitals were not. Out of 75, 35 hospitals had less than 100 beds, and 6 hospitals had between 100 and 199 beds. 14 hospitals had between 200 and 299 beds, while 13 hospitals had between 300 and 399 beds, and 7 hospitals had more than 400 beds. 63 respondents had very familiar knowledge of RFID technology, while 12 had very little knowledge.

Out of 75 respondents, only 19 have adopted RFID while 56 have not adopted yet. However, 21 out of 56 have the intention to adopt RFID technology.

As shown in Table 2, as a result of factor analysis with Varimax rotation method, 40 items of instrument measurement were grouped into 10 factors that explained $79 \%$ of variance so that 21 items of high scores of factor loading remained. Cronbach's alpha, 0.81 for factor analysis was greater than 0.70 , which meant the research instrument was highly reliable. Thus, remaining factors were competitive/strategic tools as environmental factors, and perceived benefits, trialability, and complexity as a technology factor. While innovation oriented culture and IT financial and professional resources were considered as organizational factors, consent requirements by patients and employees, privacy policy, and careful management of privacy data were well thought out as ethics/privacy factors. Using 21 variables as the reduced number of measurement, authors will conduct canonical discriminant analysis (CDA) where the dependent variable has three states, 
1) having not adopted yet and no intention to adopt, 2) having not adopted yet, but having an intention to adopt, and 3) having adopted. 35 respondents were in the first category of having not adopted yet and no intention to adopt and 21 respondents were in the second category of having not adopted yet, but having intention to adopt, while 19 respondents have adopted RFID applications.

As shown in Table 3, the result of CDA indicated that independent variables in the analysis significantly predicted three technology adoption states, because Wilks' Lambda was 0.1999 and p-value was less than 0.0001 that was smaller than 0.0004 as criteria to be statistically significant. In other words, independent variables in the analysis significantly predicted three different states of technology adoption. In other statistics, the eigenvalue for the first discriminant function, 1.4488 confirmed that the first discriminant function significantly differentiated 3 different adoption states and minimized difference within each adoption state.

According to univariate $\mathrm{R}^{2}$ analysis in Table 4, 8 variables (BENEFIT, PAT SERVICE, TRAEQ, TEST, STUDY, NETWORK, EAST-TO-USE, and RELIABLE) belonging to the technological factor showed significant difference among three adoption states at the 0.05 level. While 3 variables (INNOVATION, FINANCE, and IT PROF) representing organizational factors showed significance, 2 variables (PRIVACY POLICY - PAT DATA and PAT LOC DATA) in ethical/legal,/privacy/social factors showed significance.

Based on the multivariate analysis in Table 4, standardized coefficients of canonical structure were used to assess each variable's unique contribution to the discriminant function so that PUSH in the environment factor, TRAEQ, TEST, STUDY, NETWORK, and RELIABLE in the technological factor, FINANCE in the organizational factor, and PRIVACY POLICY -PAT DATA, PRIVACY POLICY - EMP DATA, PAT CONSENT, and EMP CONSENT in the ethical/legal/privacy/social factor showed more contribution to distinguish among adoption states because they had relatively larger coefficient values. In other words, these variables had relatively contributed more to predict three technology adoption states.
Discriminant functions for three technology adoption states in Table 5 confirmed that most variables mentioned above as a result of standardized coefficient analysis in the canonical structure in Table 4 contributed to three technology adoption states, except that INNOVATION and IT PROF belonging to the organizational factor, EMP LOC DATA and PAT LOC DATA in the ethical/legal/privacy/social factor were counted as important variables to distinguish three technology adoption states. Other exceptions were that TEST, EASY-TO-USE, and RELIABLE belonging to the technological factor did not show contribution to differentiate three technology adoption states.

Moreover, PUSH, TEST, NETWORK, RELIABLE were considered more important for $\mathrm{N}$ group (nonadopters without having an intention to adopt) than $\mathrm{Y}$ group (adopters). STUDY, PRIVACY POLICY PAT DATA, PRIVACY POLICY - EMP DATA, EMP CONSENT were considered more important for I group (non-adopters, but having an intention to adopt) than Y group while PRIVACY POLICY EMP DATA was negatively important to I group. FINANCE was considered more important for $\mathrm{Y}$ group than $\mathrm{N}$ group. TRAEQ and PAT CONSENT were considered more important for Y group than I group. Particularly, EMP LOC DATA was considered very important for all three groups of adopters.

\section{DISCUSSION}

$25 \%$ of respondents have adopted RFID technology in the diverse areas of hospitals, such as emergency room, operation room, hospital inventory and material management, pharmacy, and nursery. $75 \%$ of respondents have not adopted, while $21 \%$ of respondents had an intention to adopt in the future. Reasons why RFID technology has not been adopted or has been slow to adopt were that hospital administrators are concerned about limited budget, unproven return on investment (ROI), incompatible wireless network infrastructure, ambiguous usefulness of the technology, privacy issues, and lack of industry standard.

Based on the factor analysis, hospital administrators' perception on environmental, organizational, technological, and ethical/legal/privacy/social factors has been examined so that 2 variables (PUSH and STRATEGIC) in the environmental factors, 10 variables (BENEFIT, ERROR, PAT SERVICE, IMAGE, TRAEQ, TEST, STUDY, NETWORK, EASY-TO-USE, and RELIABLE) in the technological factor, 3 variables (INNOVATION, 
FINANCE, and IT PROF) in the organizational factor, and 6 variables (PAT CONSENT, EMP CONSENT, PRIVACY POLICY - PAT DATA, PRIVACY POLICY - EMP DATA, PAT LOC DAT, and EMP LOC DATA) in ethical/legal/privacy/social factors had high scores of factor loading and remained for further analysis. That means ethics/privacy/security factors were as important as other factors.

Results of CDA showed 21 variables were statistically significant to differentiate three states of technology adoption. Then, the analysis also showed which ones out of 21 independent variables contributed to differentiate three technology adoption states. One (1) variable (PUSH) in the environmental factor, five (5) variables (TRAEQ, TEST, STUDY, NETWORK, and RELIABLE) in the technological factor, one (1) variable (FINANCE) in the organizational factor, and four (4) variables (PRIVACY POLICY -PAT DATA, PRIVACY POLICY - EMP DATA, PAT CONSENT, and EMP CONSENT) in ethical/legal/privacy/social factor were counted as more important. That is, out of 11 reduced numbers of important independent variables predicting technology adoption states, four (4) came from ethics/privacy/security factors.

Rival hospitals that have adopted the technology seem like pushing hospital administrators as nonadopters to make an adoption decision. However, as non-adopters, hospital administrators perceive that technology should be carefully studied and fully tested before making an adoption decision. Nonadopters are concerned more than adopters that RFID applications are to be reliable and well-fitting into the existing network infrastructure.

Non-adopters having an intention to adopt RFID in the future are more concerned about the establishment of privacy policy for patients and employees before making an adoption decision. They are ethically anxious about getting the employees' consent before the adoption of RFID application, because hospital administrators can locate employees on the real time basis by RFID applications.

Financial resources are thought to be more important for adopters while non-adopters think lack of financial resources is one of the most important barriers to adopt RFID technology. Adopters perceive tracking important equipment wirelessly really benefits hospitals, and getting consent from patients before adopting the technology is ethically right because they can locate patients on the real time basis. Regardless of adopters or non-adopters, they perceive employees' location data should be carefully managed.

\section{CONCLUSION}

The authors conducted surveys to hospital administrators to investigate their perception on RFID technology and its adoption in terms of environmental, technological, organizational, and ethical/legal/privacy/social factors. As a result of factor analysis and CDA, ethical/privacy factors are as important as other environmental, technological, and organizational factors to make a technology adoption decision. Furthermore, hospital administrators who have not adopted RFID, but have an intention to adopt are more concerned about privacy policy for patients and employees. They are ethically anxious about getting employees' consent on the adoption of RFID application because hospital administrators can locate employees on the real time basis by RFID applications.

Limitations of the study are that the response rate was so low (7\%) and sample size (75) was not big enough to show statistical power even though the number of respondents met the minimum sample size to conduct factor analysis and CDA. Also, age, gender, experience, social influence, and size of hospitals are mediating variables that have not been included in the research model.

\section{REFERENCES}

1. Anonymous (2009). HIPAA Violation Costs CVS \$2.25 Millions. Information Management Journal, 43(3), 15.

2. Barlow, R. (2006). Truth or Consequences about Bar Coding: Debate Over Stripes Has Some Seeing Stars. Healthcare Purchasing News, 30(6), 78-83.

3. Barlow R. (2005). Auto ID Tug-of-War: Bar Coding vs. RFID. Healthcare Purchasing News, 29(6), 12-14.

4. Fisher, J. A. \& Monahan, T. (2008). Tracking the Social Dimensions of RFID Systems in Hospitals. International Journal of Medical Informatics, 77, 176-183.

5. Goedert J. (2009). Sorting Out the Privacy Changes. Health Data Management. 17(4), 24. 
6. Hartman, L. (2006). RFID Stays Well in Healthcare, Pharma Markets. Packaging Digest, 43(1), 42-45.

7. Kumar S., Pauly S., \& Budin,E. (2007). Impact of Radio Frequency Identification Technology on Manufacturing and Logistics: Challenges and Issues. International Journal of Manufacturing Technology and Management, 10(1), 57-70.

8. Lee, C., \& Shim, J. (2007). An exploratory Study of Radio Frequency Identification (RFID) Adoption in the Healthcare Industry. European Journal of Information Systems, 16(6), 712-724.

9. Lee, Y., \& Kenneth, K. (2008). An Empirical Investigation of Anti-Spyware Software Adoption: A Multitheoretical Perspective. Information \& Management, 45, 109-119.

10. Moore, G., \& Benbasat, I. (1991). Development of an Instrument to Measure the Perceptions of Adopting an Information Technology
Innovation. Information Systems Research, 2(3), 192-222.

11. Reiner J., \& Sullivan M. (2005). RFID in Healthcare. Healthcare Purchasing News, 29(6), 74-76.

12. Rogers, E. (1983). Diffusion of Innovations. The Free Press, New York.

13. Schuerenberg, K. (2005). Keeping Tabs with RFID. Health Data Management, 13(10), 38-48.

14. Technology Showcase: Short Video Clips of Technology Prototypes and Solutions. Available: www.accenture.com/Global/Research_and_Insi ghts/By_Subject/Radio_Frequency_Identificatio $\mathrm{n} /$ TechnologySolutions.htm?Player=Media $=1$

15. Venkatesh, V., Morris M. G., Davis, G. B., \& Davis, F. D. (2003) User Acceptance of Information Technology: Toward A Unified View. MIS Quarterly, 27(3), 425-478.

Figure 1. Research Model

\section{TABLES AND FIGURES}

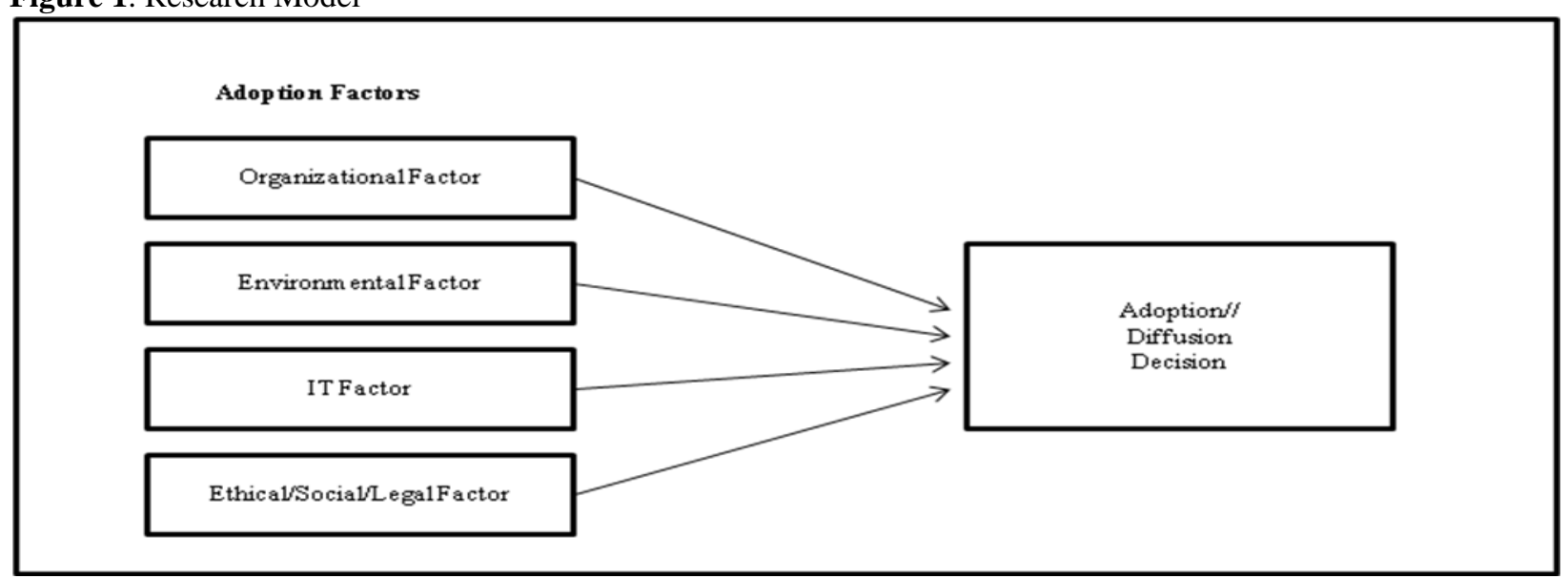


Table 1. Demographics of Respondents

\begin{tabular}{ccc} 
Gender & Program & Responses \\
\hline Female & 2 Year College Graduate & 2 \\
& Year College Graduate & 7 \\
& Graduate School Graduate & 9 \\
& Others & 2 \\
& Female Total & 20 \\
Male & 2 Year College Graduate & 2 \\
& 4 Year College Graduate & 17 \\
& Graduate CIS student & 28 \\
& Graduate MBA student & 8 \\
& Male Total & 55
\end{tabular}


Table 2. Factor Loading for Adoption Factors

\begin{tabular}{|c|c|c|}
\hline Factors & Measurement Instrument & $\begin{array}{l}\text { Factor } \\
\text { Loading }\end{array}$ \\
\hline $\begin{array}{l}\text { Environment: } \\
\text { Competitive } \\
\text { Tool }\end{array}$ & $\begin{array}{l}\text { RFID utilized in other hospitals push my hospital to adopt RFID. (PUSH ) } \\
\text { RFID is a strategic tool for competing against other hospitals. (STRATEGIC) }\end{array}$ & $\begin{array}{l}0.839 \\
0.754\end{array}$ \\
\hline $\begin{array}{l}\text { Technology: } \\
\text { Perceived } \\
\text { Benefits }\end{array}$ & $\begin{array}{l}\text { RFID has more benefits than costs. (BENEFIT) } \\
\text { RFID reduces errors for patient care. (ERROR) } \\
\text {. RFID allows the hospital to provide better patient services. (PAT SERVICE) } \\
\text { RFID improves hospital image. (IMAGE) } \\
\text {. RFID benefits hospital by wirelessly tracking important equipment. (TRAEQ) }\end{array}$ & $\begin{array}{l}0.492 \\
0.863 \\
0.871 \\
0.535 \\
0.819\end{array}$ \\
\hline Trialability & $\begin{array}{l}\text { RFID applications have been properly tested before the adoption decision. } \\
\text { (TEST) } \\
\text { Effects of RFID have been fully studied before the adoption decision. } \\
\text { (STUDY) }\end{array}$ & 0.730 \\
\hline Complexity & $\begin{array}{l}\text { Networking infrastructure in my hospital is well fit for RFID applications. } \\
\text { (NETWORK) } \\
\text {. RFID is easy-to-use technology. (EASY-TO-USE) } \\
\text {. RFID is a reliable technology. (RELIABLE) }\end{array}$ & $\begin{array}{l}0.505 \\
0.798 \\
0.853\end{array}$ \\
\hline $\begin{array}{l}\text { Organizational } \\
: \\
\text { Innovation } \\
\text { Oriented }\end{array}$ & $\begin{array}{l}\text { My hospital is oriented toward innovation. (INNOVATION) } \\
\text {. My hospital has enough financial resources to adopt RFID. (FINANCE) } \\
\text {. IS department has enough IT professionals to adopt RFID. (IT PROF) }\end{array}$ & $\begin{array}{l}0.707 \\
0.499 \\
0.628\end{array}$ \\
\hline $\begin{array}{l}\text { Ethics, Legal, } \\
\text { Privacy, } \\
\text { Social: } \\
\text { Consent } \\
\text { Requirement }\end{array}$ & $\begin{array}{l}\text { Locating patients by RFID applications without their consent is not ethical. } \\
\text { (PAT CONSENT) } \\
\text { Locating employee/staff by RFID applications without their consent is not } \\
\text { ethical. (EMP CONSENT) }\end{array}$ & $\begin{array}{l}0.929 \\
0.897\end{array}$ \\
\hline Privacy Policy & $\begin{array}{l}\text { My hospital has a policy to safely protect the privacy of patients when using } \\
\text { RFID technology. (PRIVACY POLICY- PAT DATA) } \\
\text { My hospital has a policy to safely protect the privacy of employees/staff when } \\
\text { using RFID technology. (PRIVACY POLICY- EMP DATA) }\end{array}$ & $\begin{array}{l}0.917 \\
0.924\end{array}$ \\
\hline $\begin{array}{l}\text { Private Data } \\
\text { Management }\end{array}$ & $\begin{array}{l}\text { The real time based patient location information obtained from RFID } \\
\text { applications is carefully managed. (PAT LOC DATA) } \\
\text { The real time based employee/staff location information obtained from RFID } \\
\text { applications is carefully managed. (EMP LOC DATA) }\end{array}$ & 0.608 \\
\hline
\end{tabular}


Table 3. Canonical Discriminant Analysis

\begin{tabular}{|l|l|l|l|l|l|}
\hline Statistic & Value & F-Value & Numerator DF & Denominator DF & Pr > F \\
\hline Wilks' Lambda & 0.1999 & 3.06 & 42 & 104 & $<0.0001$ \\
\hline EigenValue - Can1 & 1.4488 & 3.06 & 42 & 104 & $<0.0001$ \\
\hline EigenValue - Can2 & 1.0428 & 2.76 & 20 & 53 & 0.0016 \\
\hline
\end{tabular}

Table 4. Standardized Canonical Structure, Adjusted R-Square and Probability

\begin{tabular}{|c|c|c|c|c|c|c|}
\hline \multirow[t]{2}{*}{ Factors } & \multirow[t]{2}{*}{ Variables } & \multicolumn{2}{|c|}{$\begin{array}{l}\text { Multivariate } \\
\text { Analysis }\end{array}$} & \multicolumn{3}{|c|}{$\begin{array}{l}\text { Univariate } \\
\text { Analysis }\end{array}$} \\
\hline & & Can1 & Can2 & R-Square & $\begin{array}{c}\text { F- } \\
\text { Value }\end{array}$ & $\operatorname{Pr}>\mathrm{F}$ \\
\hline Environment: & . PUSH & 0.645 & 0.095 & 0.043 & 1.63 & 0.2034 \\
\hline Competitive Tool & . STRATEGIC & -0.177 & -0.107 & 0.017 & 0.62 & 0.5387 \\
\hline \multirow[t]{2}{*}{ Technology: } & . BENEFIT & 0.207 & -0.112 & 0.082 & 3.23 & $0.0455^{*}$ \\
\hline & . ERROR & -0.026 & 0.311 & 0.067 & 2.59 & 0.0818 \\
\hline Perceived & . PAT SERVICE & 0.236 & 0.056 & 0.093 & 3.70 & $0.0296 *$ \\
\hline \multirow[t]{2}{*}{ Benefits } & . IMAGE & -0.115 & 0.190 & 0.042 & 1.57 & 0.2142 \\
\hline & .TRAEQ & -0.363 & 1.083 & 0.257 & 12.42 & $<.0001 *$ \\
\hline \multirow[t]{2}{*}{ Trialability } & . TEST & 0.473 & 0.310 & 0.280 & 14.00 & $<.0001 *$ \\
\hline & . STUDY & 0.120 & -0.438 & 0.188 & 8.36 & $0.0005^{*}$ \\
\hline \multirow[t]{3}{*}{ Complexity } & . NETWORK & 0.607 & 0.320 & 0.226 & 10.51 & $<.0001 *$ \\
\hline & . EASY-TO-USE & -0.017 & 0.110 & 0.206 & 9.31 & $0.0003^{*}$ \\
\hline & . RELIABLE & 0.772 & -0.585 & 0.210 & 9.57 & $0.0002 *$ \\
\hline Organizational: & . INNOVATION & 0.162 & 0.097 & 0.109 & 4.40 & $0.0158^{*}$ \\
\hline \multirow{2}{*}{ Innovation Oriented } & . FINANCE & -0.391 & 0.646 & 0.084 & 3.31 & $0.0421 *$ \\
\hline & . IT PROF & -0.361 & 0.114 & 0.112 & 4.55 & $0.0138 *$ \\
\hline \multirow{3}{*}{$\begin{array}{l}\text { Ethics, Legal, Privacy, } \\
\text { and Social: } \\
\text { Consent Requirement }\end{array}$} & & & & & & \\
\hline & . PAT CONSENT & -0.474 & 0.168 & 0.001 & 0.01 & 0.9913 \\
\hline & . EMP CONSENT & 0.513 & -0.275 & 0.012 & 0.43 & 0.6533 \\
\hline \multirow[t]{2}{*}{ Privacy Policy } & $\begin{array}{l}\text { PRIVACY POLICY } \\
\text { - PAT DATA }\end{array}$ & 0.911 & -0.838 & 0.109 & 4.39 & $0.0158^{*}$ \\
\hline & $\begin{array}{l}\text { PRIVACY POLICY } \\
\text { - EMP DATA }\end{array}$ & -0.996 & 1.172 & 0.074 & 2.86 & 0.0640 \\
\hline Private Data & . PAT LOC DATA & 0.190 & 0.137 & 0.175 & 7.62 & $0.0010^{*}$ \\
\hline Management & . EMP LOC DATA & 0.130 & -0.152 & 0.054 & 2.04 & 0.1378 \\
\hline
\end{tabular}

Note: * indicates variable is significant at .05 level 
Table 5. Discriminant Function for Three Adoption States (N: No Intention to Adopt, I: Intention to Adopt, but having not adopted yet, $\mathbf{Y}$ : Adopted)

\begin{tabular}{|l|l|r|r|r|}
\hline \multicolumn{1}{|c|}{ Factors } & \multicolumn{1}{c|}{ Variables } & \multicolumn{1}{c|}{$\mathrm{N}$} & \multicolumn{1}{c|}{$\mathrm{I}$} & \multicolumn{1}{c|}{$\mathrm{Y}$} \\
\hline Environment: & . PUSH & 5.346 & 5.096 & 3.372 \\
Competitive Tool & . STRATEGIC & 0.394 & 0.678 & 1.031 \\
\hline Technology: & . BENEFIT & 0.928 & 1.311 & 0.262 \\
& . ERROR & 3.107 & 1.987 & -2.798 \\
Perceived & . PAT SERVICE & 1.116 & 0.503 & 1.308 \\
Benefits & . IMAGE & -2.168 & -1.936 & -1.314 \\
& .TRAEQ & 8.790 & 5.035 & 8.822 \\
Trialability & . TEST & & & \\
& . STUDY & 2.773 & 1.782 & 0.700 \\
Complexity & & 2.634 & 4.096 & 2.421 \\
& . NETWORK & & & \\
& . EASY-TO-USE & 8.374 & 7.487 & 6.150 \\
Organizational: & . RELIABLE & 1.275 & 0.906 & 1.204 \\
Innovation Oriented & . INNOVATION & 1.289 & 3.281 & -0.964 \\
\hline Ethics, Legal, Privacy, and & . FINANCE & -3.969 & -4.230 & -3.572 \\
Social: & . IT PROF & 5.148 & 3.671 & 5.612 \\
Consent Requirement & . EAT CONSENT & -2.773 & -3.021 & -1.961 \\
\hline Privacy Policy & . CONSENT & 1.819 & 1.435 & 2.919 \\
& . PRIVACY POLICY - PAT DATA & 3.074 & 3.695 & 1.984 \\
Private Data Management & . PRIVACY POLICY - EMP DATA & 1.546 & 4.008 & -0.585 \\
& & 0.661 & -3.075 & 2.884 \\
& . PAT LOC DATA & 3.629 & 3.045 & 2.503 \\
\hline
\end{tabular}

